\title{
Digitized German editions of the 18th - 19th centuries as non-academic sources of Armenology: history reflected in postmodernity
}

\author{
Besarion Meskhi ${ }^{1}$, Svetlana Ponomareva ${ }^{1}$, Olga Fedotova ${ }^{1 *}$, Haykaz Hovhannisyan ${ }^{2}$, \\ and Vladimir Latun ${ }^{3}$ \\ ${ }^{1}$ Don State Technical University, 344003, Rostov-on-Don, Russia \\ ${ }^{2}$ Yerevan State University, 0025, Yerevan, Armenia \\ ${ }^{3}$ Southern Federal University, 344007, Rostov-on-Don, Russia
}

\begin{abstract}
The article discusses the problems of using archival materials and old editions in order to familiarize themselves with the history and culture of individual countries. Using the example of the practice of postmodern technology for digitizing non-academic historical documents by German authors, it is shown that they constitute a significant resource for expanding knowledge in the field of cultural studies, educational history, historical geography due to the presence of a text array and visual range. Visual imagery includes a wide range of artifacts, including national and military clothing, national symbols, historical geopolitical maps. Digitized editions of the 18th and 19th centuries, devoted to the problems of the history and culture of the Armenian people, being descriptive material, make a great contribution to the formation of a new scientific direction in Armenology. They allow you to get acquainted with authentic historical documents containing information about the geopolitical, historical, social, cultural, philosophical and pedagogical problems of the Caucasus in the 18th century. and XIX centuries. The article shows that subsequent scientific research on the problems of the history of the peoples of the Caucasus did not become widely known due to the lack of available digitalized historical sources containing the works of both Armenian and foreign authors.
\end{abstract}

\section{Introduction}

The modern world rises to a new stage of its development, characterized by the global availability of information and the ability to overcome borders between countries, to get acquainted with their culture, mentality, traditions. The transition to new information formats in the form of Internet technologies creates unique prerequisites for getting acquainted with the historical past of peoples, its value orientations, cultural artifacts and mental foundations.

The fact that the past is an important factor in understanding modern development trends is not disputed by modern historians, cultural scientists, political scientists and sociologists. It updates the attention of researchers to the first attempts to systematically represent the cultural heritage of other peoples in pedagogical discourse [1]. Armenia is currently in the

\footnotetext{
*Corresponding author: fod1953@yandex.ru
} 
focus of attention of the world community. The cultural heritage of that country is deeply rooted $[2,3,4]$. The topics of the history of Armenia are the object of Armenian studies, the interest in the problems of which was observed among scientists from many countries $[5,6]$. The works of German and Russian researchers play a special role in the study of the history of the Armenian people and statehood.

In the 19th century, which was destined to introduce qualitative and quantitative changes in the study of Armenia and the history of the Armenian people, the process of the formation of Russian and German historiographic thought was completed. It developed in two main directions: the creation of historiographic concepts and the strengthening of the source study base. On the one hand, proceeding from this practical historiographic necessity, interest in the study of the history of the annexed peoples, including the history of the Armenian people, has increased in Russian scientific circles. On the other hand, if in the 18th century the problems of the history of Armenia did not receive their scientific development, then in the 19th century voluminous and serious scientific research appeared. And, despite a certain similarity in the points of view of Russian historians on the history of Armenia, in the scientific heritage of each historian there are many different approaches, which explains a certain interest in this heritage. The conclusions contained in these studies and the rich factual material in many respects help to re-evaluate certain issues of the history of Armenia.

The main idea of this study is to determine what is the qualitative originality of the historical sources of the 18th and 19th centuries, which became available to readers due to their transformation into a digitized document; how much non-academic historical literature helps to study the problems of the history of the Armenian people and whether it is a factor in the molding impact.

\section{Methodology and Methods}

The purpose of the study is to determine the sequence and specificity of those historical documents and non-academic materials that formed the basis of Armenian studies in the 18th - 19th centuries and laid the foundation for the study of the problems of Caucasian issues in Russia and abroad as a separate area of scientific knowledge.

The empirical source are the printed sources of the 19th century (in Armenian and Russian) and digitized publications, which are digitized and therefore widely available works of German authors of the 18th and 19th centuries, containing information and materials on the problems of the formation and development of the Transcaucasus.

Research methods - comparative analysis [7], content analysis [8], description, interpretation, generalization, classification, cluster method.

When carrying out content analysis, the conceptual category of analysis was the category of "Armenia", presented in all sorts of semantic variants. The unit of account was a publication of monographic level, indexed in bibliographic Internet sources.

For graphic design of the results the EXCEL program was used.

\section{Results}

The first stage of the study was devoted to determining the sequence of the appearance in the Russian and German scientific discourse of documents of the 18th and 19th centuries, as well as materials and information that make it possible to determine the informational array of future Armenology as an independent research area of geopolitical, historical, social, cultural, philosophical and pedagogical problems of Caucasian studies. A thematic search was carried out for publications contained in electronic resources. We used electronic catalogs, information bases, libraries, websites of research organizations. 
As result of the search, publications of a monographic level, devoted to the history and culture of the Armenian people, were found, studied and systematized according to the criterion "year of publication". The results of the search and selection of sources are presented in chronological order (see Fig.1).

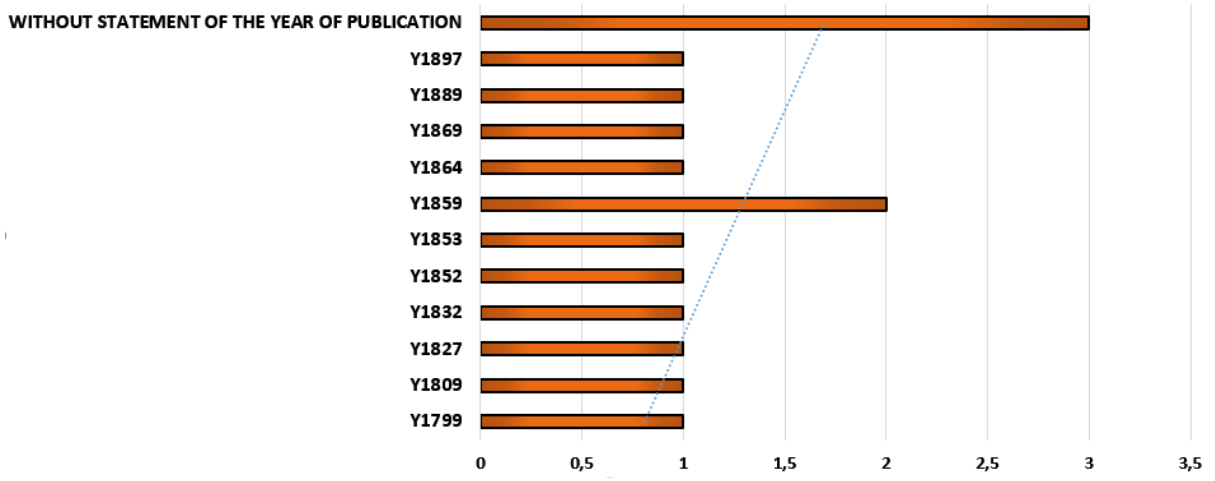

Fig. 1. Monographic publications on the history and culture of the Armenian people, published in the 18-th and 19-th centuries.

Figure 1 shows the works of the authors, whose appearance fell on a difficult period, when the process of the formation of Russian historiography was not completed in Russia itself. Historiographic thought at that time developed in two main directions: the creation of historiographic concepts and the strengthening of the source study base. Proceeding from this practical historiographic necessity, interest in the study of the history of the peoples newly annexed to Russia, including the history of the Armenian people, has increased in scientific circles.

The lack of reliable scientific information about the peoples of the Caucasus, including those that later became part of the Russian Empire, was partially made up for by foreign sources. A significant role in expanding the understanding of geopolitical and historicalcultural constants was played by German travelers, researchers, diplomats, and the military, who had information about the life of the Armenian population and who took the trouble to present this information in writing.

As shown in Figure 1, one of the first editions that systematically presented facts about the life of the Armenian people was the four-volume work of the German author Johann Gottlieb Georgi [9], which was translated into Russian and published in Russia in 1799. This work is a source of information not only of a historical nature, but also gives an idea of the culture, education, crafts of the Armenian population in the 18th century. The modern reader has the opportunity to familiarize himself with the content of this publication thanks to the presence of a digitized copy. In particular, this publication describes in detail the history of the resettlement of the Armenian population from Persia, Georgia, Turkey, Crimea.

The Russian translation describes in detail the circumstances of the resettlement of Armenians in the southern limits of the Region of the Don army and the creation of the city of Nakhichevan, about the self-designation of the Armenians and their preservation of religion. The emphasis is on the fact that Armenians "speak their own language, and write in it, with all the special letters. Their language has nothing in common with other Eastern languages, except for the way of expression. Their schools are hefty" [9].

Thanks to the availability of digitized copies, our contemporaries have the opportunity to familiarize themselves with the traditional clothes of Armenians, which are captured on color engravings (see Fig. 2). 


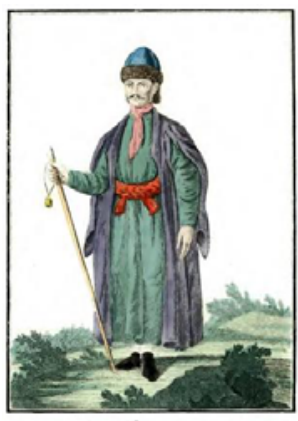

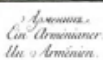

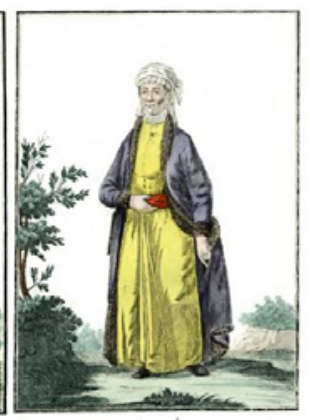

Cine brimolat

Fig. 2. Traditional clothes of Armenians of the 18th century [9, pp. 48-49].

When describing the national men's costume, the emphasis is on the advisability of wearing warming scarves in winter, the absence of tightening fasteners on caftans and the presence of a traditional headdress with a fur band with a four-piece crown. In women's clothing, the author pays special attention to expensive fabrics, embroidered sashes and expensive sewing, the presence of expensive jewelry that complements even the most modest outfit. Attention is drawn to piety, the modest lifestyle of even very well-to-do families, to thrift, simplicity of food and kind-heartedness [10].

German sources provide the reader with a rare opportunity to get acquainted with the geopolitical schemes of the past. Before the entry of certain regions and territories of Georgia, Dagestan and Eastern Armenia into the Russian Empire after the end of the RussianPersian War (1826 - 1828), the state of geopolitical coordinates was recorded in W. Freygang's work "Letters about the Caucasus and Georgia" [11] (see Fig. 3).

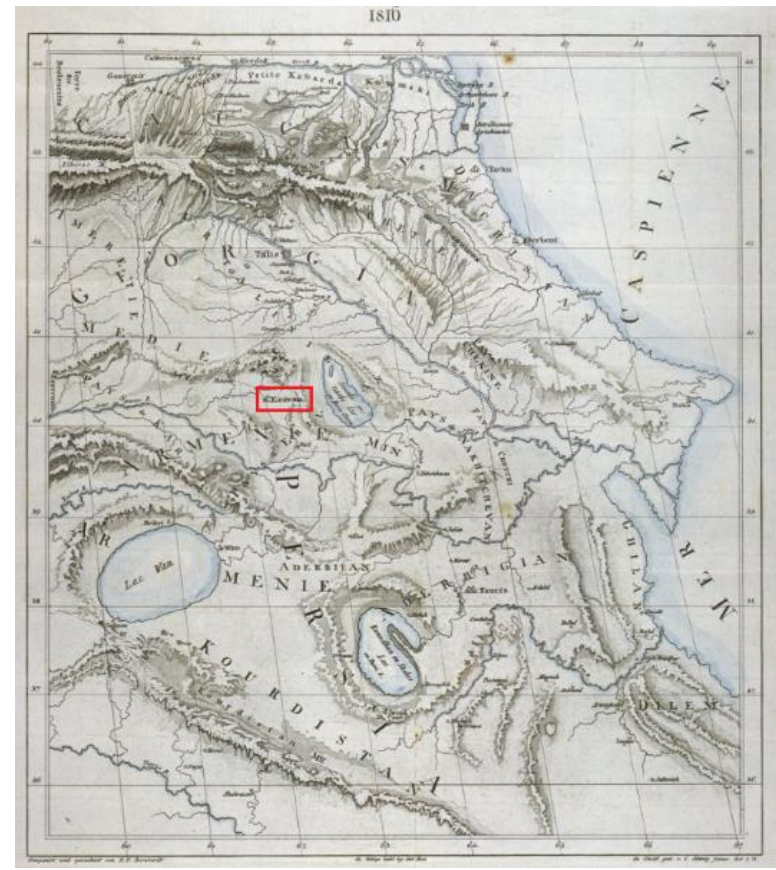

Fig. 3. Map of the Caucasus and parts of Persia with the location of the territory of Armenia and the city of Yerevan in 1816 [11]. 
As evidenced by the geopolitical map, on the depicted territory inhabited by the peoples of the Caucasus, during the period of its compilation, there were no clear boundaries between Georgia, Azerbaijan, Kurdistan, Persia. At the same time, the resources of the territory are clearly marked on the map - water resources, which are a strategic reserve and a source of life.

Geographic objects are also represented in other images that have reached the general reader due to the phenomenon of digitization of materials (see Fig. 4).
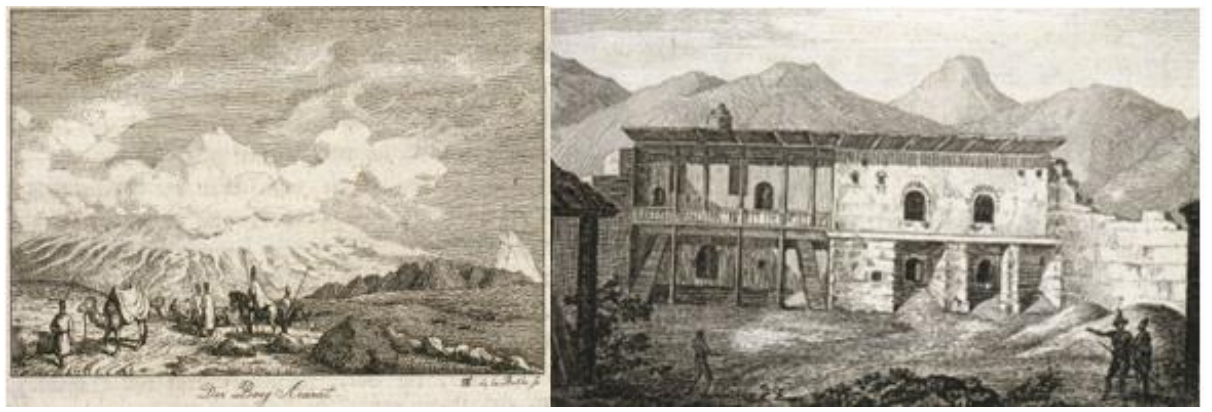

Fig. 4. Images of military units against the background of Mount Ararat and traditional houses [11].

The nature of the images of national costumes, dwellings, geographical objects, as well as the accompanying author's commentary allows us to conclude that at the end of the 18th century - at the beginning of the 19th century, information was presented mainly in a descriptive form and contained, among other things, critical assessments. The object of the description was everyday rituals, clothing, dwellings, religions, routes of movement, landscapes, everyday episodes. Based on the analysis of the visual range and text descriptions, it can be concluded that in the 18th and early 19th centuries. the problems of the history and culture of Armenia have not received their systematic development. Nevertheless, they can be separated into a separate cluster, uniting the works of German authors that preceded the development of Russian Armenology.

The second stage of the study focuses on 19th century research. In the 19th century, voluminous and serious scientific studies were published. Despite a certain similarity in the points of view of Russian and foreign historians on the history of Armenia, in the scientific heritage of each author there are many different, original approaches.

In 1809, the book of the founder of Armenian historiography Moses Khorensky "Armenian History" [12] was translated into Russian and published, followed by the works of other Armenian historians. The primary task of Armenian historians was the need to provide the Russian reader with the rich history of the Armenian people and show its definite role in the historical events of Asia Minor: and it is no coincidence that one of the first works published in Russian was the study of S.N. Glinka [13, 14], brothers Yakov and David Arzanov [15]. It was published in 1827, during the Russian-Persian war of 1826-1828. It is not difficult to notice that this circumstance had not only Armenian studies, but also an important political significance.

The historian Alexander Khudobashev [16], as follows from his publication, was not only distinguished by his knowledge of ancient Armenian sources, but also had a rich library of these works. The first acquaintance of the Russian reader with the history of the Armenian people took place. The second half of the century in the history of the Russian state, especially after the reforms of the $60 \mathrm{~s}$ and $70 \mathrm{~s}$, was marked by a new stage in the country's development. Many Russian historians have joined the famous Caucasian scholars P. Butkov [17], N. Dubrovin [18] and V. Potto [19].

Historiographic Armenian studies thought gradually developed in Russia. Russian periodicals published materials concerning both Armenia and individual issues of the history 
of the Armenian people. Many leading representatives of Russian historical thought not only developed scientific problems of the history of Armenia, but also expressed support for the Armenian people in their national liberation struggle. In this respect, the collection "Fraternal assistance to the Armenians who suffered in Turkey", published in Moscow in 1897, stands out [20]. A number of Armenian historians-Armenologists, who studied at leading Russian universities, grew up in the centers of Armenian Studies and gained wide scientific fame. Outstanding representatives of this school were Mkrtich (Nikita Osipovich) Emin [21], K.P. Patkanov [22] and G. Ezov [23]. Thanks to them, the political, socio-economic and cultural history of Armenia was largely generalized in Russia.

\section{Conclusion}

Modern technologies for preserving cultural heritage allow a wide range of readers to get acquainted with materials and documents that would not be available for them in print. Germany plays a great advantage in the preservation and creation of electronic archives as a country with deep historical and cultural traditions. The careful attitude of German scientists to the cultural heritage of other countries makes available large amounts of information, including both analytical and illustrative components. The presence of the opportunity to familiarize with authentic historical documents and materials is a significant factor in the molding influence. The study of the history and culture of the people using digitized sources allows you to feel the spirit of the times, to assess the position of the author who lived in a particular historical era. These works provide their readers with an opportunity to give a new and fair assessment of the history of the Armenian people and Armenia as a whole.

At the same time, the academic assessment as to how the presented materials correspond to the current standards of historical science does not play a significant role. It is more important to feel the spirit of the times and the mood of the authors regarding the historical past of the Armenian people and their cultural heritage. It should be noted that the listed publications are not available to the broad masses of those interested in the history and culture of Armenia, since they are not digitized and are not available for free access to all interested readers.

\section{References}

1. H. Chakaryan, J. Laux, International journal for the advancement of counselling 41(3), 376-388 (2019). doi: 10.1007/s10447-018-9356-9.

2. Y. Margaryan, Dialog so vremenem - Dialogue with time 65, 207-228 (2018). doi: 10.21267/AQUILO.2018.65.20770.

3. O. Fedotova, P. Ermakov, V. Latun, H. Hovhannisyan, et. al., Journal of fundamental and applied sciences 9, 1354-1368 (2017). doi: 10.4314/jfas.v9i7s.123.

4. O. Fedotova, P. Ermakov, V. Latun, Hovhannisyan et al., Journal of Social Studies Education Research 8(S), 150-165 (2017)

5. A. Galstyan, Tomsk State university journal of history 3, 73-78 (2015). doi: 10.17223/19988613/35/11.

6. T. Hoch, Soviet and PostSoviet review 47(23), 306-332 (2020). doi: 10.30965/18763324-20201370.

7. O. Fedotova, O. Chigisheva, International Perspectives on Education and Society 26, 5782 (2015). doi: 10.1108/S1479-367920140000026003.

8. O. Fedotova, Middle East Journal of Scientific Research 16(3), 392 - 396 (2013). doi: 10.5829/idosi.mejsr.2013.16.03.11691. 
9. J.G. Georgi, Description of all nations of the Russian Empire, their way of life, religion, customs, housing, clothing and other oddities (Beschreibung aller Nationen des Russischen Reichs, ihrer Lebensart, Religion, Gebräuche, Wohnungen, Kleidung und übrigen Merkwürdigkeiten) (C.W. Müller, St. Petersburg, 1776-1780)

10. E. Thuno, Convivium-exchanges and interactions in the arts of medieval Europe byzantium and the Mediterranean 3(S), 144-159 (2016)

11. Freygang, Wilhelm von: Letters about the Caucasus and Georgia. (Briefe über den Kaukasus und Georgien) (Without specifying the publisher, Hamburg, 1817)

12. Moses Khorensky, An Armenian history composed by Moses Khorensky: with a brief geographical description of Ancient Armenia (Part 2. Medical publishing house, St. Petersburg, 1809)

13. S.N. Glinka, Review of the history of the Armenian people from the beginning of its existence to the revival of the Armenian region in the Russian Empire (Publishing House Lazarevs, Moscow, 1832-1833)

14. S.M. Sayadov, Bylye gody 50(4), 1471-1482 (2018). doi: 10.13187/bg.2018.4.1471.

15. Ya. Arzanov, Experience of tracing the history of the Armenian kingdom (Semyon Selivanovsky, Moscow, 1827)

16. A.M. Khudobashev, Overview of Armenia in Geographical, Historical and Literary Relations (Second Department of the Chancellery, St. Petersburg, 1859)

17. P.G. Butkov, Materials for the new history of the Caucasus, from 1722 to 1893 (Publishing House of the Imperial Academy of Sciences, St. Petersburg, 1869)

18. N.F. Dubrovin, Materials for the history of the reign of Alexander I. Turkish War 18061812.

19. V.A. Potto, The first volunteers of Karabagh in the era of the establishment of Russian rule (Melik-Vani and Akop-Vuzbashi Atabekovs) Yerevan.

20. Fraternal assistance to the Armenians who suffered in Turkey (Education-South, Krasnodar, 2014)

21. N.O. Emin, Essay on the religion and beliefs of pagan Armenians (Publishing House Lazarevs, Moscow, 1864)

22. K.P. Patkanov, Research on the dialects of the Armenian language: a philological experience (URSS, LENAND, Moscow, 2016)

23. G.A. Ezov, The inner life of ancient Armenia (Naval ministry, St. Petersburg, 1859) 